\author{
Prof. Dr. Achim Zink
}

\title{
Der Bausparvertrag
}

3. Auflage 
CIP-Kurztitelaufnahme der Deutschen Biblothek

Zink, Achim:

Der Bausparvertrag / Achim Zink. - 3. Aufl. Wiesbaden: Gabler, 1984.

1. Auflage 1981

2. Auflage 1982

3. Auflage 1984

(C) Betriebswirtschaftlicher Verlag Dr. Th. Gabler GmbH, Wiesbaden 1984 Umschlaggestaltung: Horst Koblitz, Wiesbaden

Alle Rechte vorbehalten. Auch die fotomechanische Vervielfältigung des Werkes (Fotokopie, Mikrokopie) oder von Teilen daraus bedarf der vorherigen Zustimmung des Verlages. 


\title{
Der Bausparvertrag
}

\author{
Von Prof. Dr. Achim $\mathrm{Z}$ i n k
}

\section{Inhaltsverzeichnis}

I. Das Bausparen . . . . . . . . . . . . . . . . . . 7

1. Die Anfänge . . . . . . . . . . . . . . 7

2. Die Bedeutung des Bausparens in der Bundesrepublik . . . . . 8

3. Das Kollektivmodell . . . . . . . . . . . . . . . . . . 12

II. Ablauf des Bausparvertrages . . . . . . . . . . . . . . . . 14

1. Verwendungsmöglichkeiten des Bausparvertrages . . . . . . . 14

2. Vertragsablauf . . . . . . . . . . . . . 15

3. Förderung des Bausparens . . . . . . . . . . . 16

4. Die Bewertungszahl . . . . . . . . . . . . . . . 20

5. Kündigung vor Zuteilung . . . . . . . . . . . 23

III. Abschluß des Bausparvertrages . . . . . . . . . . . . . 25

1. Antrag, Annahme, Vertragsbeginn ... . . . . . . 25

2. Tarife ..................... 25

3. Bausparsumme ................. . . 27

4. Abschlußgebühr . . . . . . . . . . . . . . 29

5. Gemeinschaftsvertrag ............. . 31

6. Begünstigung eines Dritten . . . . . . . . . . . 31

IV. Bausparguthaben .................. 33

1. Regelsparbeiträge ................ . 33

2. Sonderzahlungen ................. . . . . 34

3. Verzinsung des Guthabens . . . . . . . . . . . . 35

V. Änderung des Bausparvertrages . . . . . . . . . . . . . 37

1. Teilung ................. . . 37

2. Ermäßigung ................... 38

3. Zusammenlegung .............. . . 39

4. Erhöhung ................... 40

5. Übertragung .................... 42

VI. Zuteilung des Bausparvertrages . . . . . . . . . . . . . . . 45

1. Zuteilung und Zuteilungsmasse . . . . . . . . . . . . . . 45

2. Voraussetzungen und Reihenfolge der Zuteilung . . . . . . . . . 47

3. Zuteilungsverfahren ... . . . . . . . . . . . 50

4. Wartezeit .................. 51 
VII. Darlehensgewährung und Tilgung . . . . . . . . . . . . . 53

1. Kreditwürdigkeit des Bausparers bzw. Darlehensnehmers . . . . 53

2. Beleihungswert ................ 54

3. Sicherung des Bauspardarlehens . . . . . . . . . . . . 55

4. Auszahlung des Bauspardarlehens ... . . . . . . . . 56

5. Verzinsung und Tilgung des Bauspardarlehens . . . . . . . 57

6. Sondertilgung .................. 63

7. Laufzeit eines Bauspardarlehens . . . . . . . . . . . 64

VIII. Antworten zu den Fragen . . . . . . . . . . . . . . . . . . 68

IX. Anhang . . . . . . . . . . . . . . . . . . . . 76

1. Tabellen- und Abbildungsverzeichnis . . . . . . . . 76

2. Verzeichnis der Mitglieder des Verbandes der Privaten Bausparkassen . 76

3. Verzeichnis der Landesbausparkassen . . . . . . . . . . . . . . 77

4. Allgemeine Bedingungen für Bausparverträge der Privaten Bausparkassen (Musterbedingungen) . . . . . . . . . . . . . . . . . . . 79

5. Allgemeine Bedingungen für Bausparverträge der Landesbausparkassen (Musterbedingungen) . . . . . . . . . . . . . 92

Stichwortverzeichnis . . . . . . . . . . . . . . . . . . 109 